Fecha de recepción: marzo 2017 Fecha de aceptación: octubre 2017 Versión final: marzo 2019

\section{Marcas de shopping o de diseñador. Los procesos de adscripción en la moda}

Bárbara Guershman *

Resumen: El objetivo de este artículo consiste en comprender de qué forma se desarrollan los procesos sociales de adscripción, en función de cómo un grupo de productores de indumentaria (prendas de vestir, calzado y accesorios) intervienen en eventos y exhibiciones bianuales de moda. El presente escrito está basado en el trabajo de campo etnográfico realizado para mi tesis de doctorado. Fue en el curso de dicho trabajo que advertí la relevancia de dos categorías: marca y diseñador. Estas categorías remiten a la forma en la cual esos productores se identifican públicamente. Constituye una identificación relativa al volumen de prendas que conforman su producción por temporada, los espacios sociales donde comercializan la indumentaria, así como las imputaciones morales respecto a la presencia de la copia. Esta copia expresa la mayor o menor influencia de tendencias internacionales de moda en un producto propio o la carencia de características propias del autor-diseñador.

Quienes son reconocidos como diseñadores, pretenden estar alejados de estas tendencias. Por otra parte, sus colecciones incluyen menos prendas que las marcas, las cuales se caracterizan por venderse en shopping, centros comerciales ubicados en CABA y conurbano. Pero esta distinción se pone en cuestión en varios contextos llevando a que las categorías de marca y diseñador se articulen entre sí. Es una articulación que describiré en el escrito.

Palabras clave: diseño - moda - indumentaria - producción - comercialización.

[Resúmenes en inglés y portugués en las páginas 142-143]

${ }^{(*)}$ Magister en Antropología (IDEAS- UNSAM). Docente de grado en la Universidad Nacional Arturo Jaureche, en la Universidad de Belgrano y en la Universidad del Este. Estudia desde hace más de 5 años desde una perspectiva antropológica el diseño de indumentaria y ha integrado proyectos de investigación UBACYT y PIP en ese marco. Asimismo ha sido expositora de numerosos congresos nacionales e internacionales cuanto ha publicado en esas mismas esferas.

\title{
Introducción
}

El objetivo del presente artículo consiste en comprender cómo se desarrollan los procesos de adscripción en el campo de la moda de CABA (Ciudad Autónoma de Buenos Aires). 
Para ello, comenzaré por hacer referencia a mi trabajo de campo etnográfico puesto que, a partir del mismo, es como llegué a ahondar en los múltiples usos de lo que considero las dos principales categorías "nativas" dentro del campo: diseñador y marca.

Este trabajo se inició en el 2005 y se extendió a la actualidad, con una eventual interrupción para completar la tesis de maestría, defendida en el 2009. A lo largo de estos años, he venido -de forma recurrente- realizando entrevistas no dirigidas a productores de ropa. Asimismo, a organizadores de eventos, gerentes de marketing, maquilladores, peinadores, estilistas y productores ${ }^{2}$. Asimismo, he realizado observaciones (con mayor o menor grado de participación ${ }^{3}$ ) en sesiones de fotos, desfiles y celebraciones de apertura de locales de venta al público. Finalmente, la investigación incluyó la recopilación de artículos de revistas, suplementos y folletos dedicados a la temática del diseño y la moda.

Fue en el curso de esta investigación que reparé en una distinción realizada por los entrevistados respecto a los productores: ser una marca comercial o ser diseñador. El lector habrá advertido que a ambas categorías les agregué el verbo ser. Esta inclusión, lejos de ser casual, obedece a la propia forma en la cual los productores se presentan. En vez de plantear que fundaron tal empresa o emprendimiento, emplean expresamente ese verbo vinculado con la marca, que denota su identidad.

La identidad es un asunto que, según Claude Levi-Strauss (1981), puede ser tratado en dos niveles: el correspondiente al sujeto individual y al nivel grupal referido a la identidad étnica. En este sentido, el autor señala que el nombre propio remite tanto a la inscripción social del sujeto en un grupo como la identidad de la persona misma. ¿Es posible discriminar realmente ambas dimensiones? Si asigno mi nombre a una empresa o fundación ¿se trata del sujeto que asigna tal denominación o estamos hablando de un nivel grupal que da cuenta del vínculo entre el productor y el conjunto de personas que tratan con él? Durante años, presumí que la distinción antes mencionada era excluyente, lo cual significaba que se era una cosa o la otra. Pero esta sospecha fue posteriormente descartada en el curso de las entrevistas y observaciones. Mas aún, se complejizó. Para algunos productores, la distinción era excluyente y lo sigue siendo. Otros la ampliaron al señalar que se consideraban marcas y diseñadores a la vez. Algunos se identificaron como marcas de diseñador en contraposición a las marcas de shopping. Entendí así que la identidad de quienes producen ropa resultaba más vasta que una mera oposición de categorías, por lo cual debía atender a las formas en las cuales las mismas se articulaban.

Este artículo trata, como indiqué previamente, acerca de los procesos de adscripción en el cual se ven implicados los productores de ropa y quienes participan junto a ellos en la moda: modelistas, dueños de talleres de confección, productores de desfiles, maquilladores, gerentes de marketing y jefes de producto. Me interesa dar cuenta de los contextos en los cuales se desarrollan estos procesos que están ligados a la identidad, en el sentido que lo plantea Fredrik Barth (1976). Para este antropólogo noruego, la identidad étnica remite al término de límite referido, a su vez, a las categorías de adscripción que son empleadas por los actores mismos y al mismo tiempo, regulan la interacción entre estos.

Lo que este autor propone es que el límite social es lo que define al grupo y no el contenido. Esto es: lo que nos separa de otros nos define. Lo que propongo desarrollar en este trabajo, basándome en la perspectiva de Barth acerca de la identidad como un proceso dinámico, son las formas en las cuales se constituye la auto y hétero adscripción, en el caso 
de los productores de ropa y cuáles son las situaciones en las que estas formas se ponen en cuestión.

\section{Las colecciones y sus escalas}

En primer lugar, el ser reconocido por otros -a la vez que reconocerse a uno mismo-como un diseñador o una marca depende del número de prendas que un productor confecciona por temporada. Este conjunto de prendas se llama colección. Lo que varía entre los productores es precisamente la cantidad de prendas que confeccionan en correspondencia con las dimensiones de su negocio. Es decir, cuantos locales o "puntos de venta" detentan. A estas dimensiones se refirió Paulina, quien es la jefa de producto ${ }^{4}$ de la sección dedicada a la elaboración de prendas de denim. Dicha sección forma parte de "Antea" que es una cadena de indumentaria de origen chileno. Creada en 1989, esta empresa posee tiendas departamentales situadas en diferentes ciudades de América Latina. En estas tiendas se comercializa indumentaria masculina, femenina e infantil. Además, muebles, equipos de electrónica y electrodomésticos.

Antes de trabajar en Antea, una marca grande como la describió Paulina, ella trabajó en el mismo puesto del "departamento de producto" de otra empresa fundada por una diseñadora quien empleó su nombre y apellido para registrarla como "María Rodríguez"6. Actualmente, la marca cuenta con doce locales. Seis de ellos están situados en centros comerciales.

Con Paulina nos encontramos en el patio de comida de un centro comercial situado junto a la autopista, el límite entre el barrio porteño de Núñez y la localidad de Martínez, al norte del conurbano bonaerense. El patio de comidas, que incluye varias cadenas de restaurantes, está emplazado en el tercer piso. A la hora en la cual nos encontramos, en su horario de almuerzo, costaba hallar mesas libres donde acomodarnos.

Una de mis primeras preguntas fue cómo ella distinguía el trabajo realizado en una marca de diseñador de otra que no lo era. Meditó unos instantes y comenzó por indicar que la marca de diseñador tiene una identidad, un sello definido y propio, más allá de que en ésta se tengan en consideración las tendencias de moda mundiales. Pero el seguimiento de las tendencias tiene sus matices. Todos los que producen ropa las tienen en consideración -subrayó Paulina- lo que varía es cuan significativa es esta influencia sobre ellos.

La copia constituye una cuestión ambigua en el mundo de la moda, señala Alec Balacescu (2005) debido a que constituye una práctica condenada moralmente y reproducida por los diseñadores cuando producen ropa. Para este antropólogo, es difícil determinar que constituye una copia, más allá de las legislaciones que salvaguardan los derechos del autor de una obra ante posibles falsificaciones. Si bien es inevitable que la copia se haga presente en el proceso de creación de una prenda, la dificultad radica en donde identificarla. Desde la perspectiva de los diseñadores iraníes con quienes él realizó su investigación, los habitantes de Teherán -capital de Irán- consideran que todo es pasible de ser imitado: la ropa así como estilos de vestir parisinos, difundidos por canales de moda. ¿La imitación constituye una copia? Es ahí donde radica la ambigüedad. En el curso de mi trabajo de campo, esa ambigüedad se expresaba cuando los diseñadores argumentaban que ellos, lejos de 
copiarse, se inspiraban en tendencias provenientes de los centros de moda. No eran estas el objeto de la condena moral, sino como la forma en la cual eran apropiadas.

Diez años antes de mi almuerzo con Paulina, otra diseñadora llamada Vanina se refirió a tal apropiación con un ejemplo. Comentó que, en la temporada del 2005, estaban de moda las cadenas doradas. Aunque las consideraba de "mal gusto", no las podía obviar en la colección porque se las pedían las clientas. En consecuencia, adecuaba este adorno al estilo de su propia marca. Junto con otros diseñadores, fundó una marca dedicada a la producción de accesorios para mujeres, fabricados con elementos de descarte: mangueras, neumáticos de auto y cuentas de goma. Si bien ella no podía obviar lo que estaba de moda, lo adaptaba a su forma de hacer ropa. Otros diseñadores planteaban que la reproducción constituía una copia cuando una modelista replicaba en un vestido la moldería correspondiente a otro vestido. Teniendo en cuenta la ambigüedad señalada por Balacescu, el desafío es establecer cuáles son los límites (si es que se pueden establecer límites nítidos) entre la adaptación, la adecuación, la inspiración y la mera reproducción de las bases de moldería de un vestido o elaborar una cadena dorada con plásticos de descarte.

Sumado a la cuestión controvertida de la copia, que será retomada posteriormente, otra dimensión de la diferencia entre una marca comercial y una marca de diseñador es el volumen de ropa que se produce y cómo se produce. En este sentido, Paulina caracterizó la ropa de María Rodríguez como: "más exclusiva y manual, más cara y menos industrializada”. En María Rodríguez, ella trabajaba con un equipo de diseñadores que realizaban prendas de forma artesanal, por lo cual el producto ${ }^{7}$ les resultaba más caro de confeccionar. La complejidad en la hechura de las prendas implicaba dificultades al procurar hallar talleres textiles dispuestos a realizarlas. Su confección requería más tiempo de trabajo, lo cual incrementaba su precio. Como si mantuviera un diálogo imaginario con el dueño de un taller y fuera éste el que replicara, Paulina concluyó: "Sí te podemos hacer 100, 500 ya es muy difícil para nosotros. ¿Entendés?”

A los volúmenes hizo alusión Marianela, ex jefa de producto que trabajó en una empresa dedicada a la fabricación de calzado que tiene varias sucursales en CABA y otras ciudades al interior de Argentina. La entrevisté en su departamento, situado en el barrio de Palermo. Mas precisamente, en el área llamada "Palermo Soho" ${ }^{8}$. En este departamento, de dos ambientes, realizaba ferias durante los fines de semana donde exhibía vestimenta de diseñadores quienes se la entregaban en consignación para que la vendiera. Al hacerlo, Marianela aplicaba un porcentaje al precio de la vestimenta, colgada en percheros metálicos. Si no se vendía, la devolvía. En las marcas donde ella trabajó antes de iniciar las ferias -señaló- se hacían cantidades grandes. A modo de ejemplo, contrastó las 1000 unidades de una colección de una marca a partir de cada modelo, respecto a los 10 o los 20 modelos realizados por los diseñadores.

Si la copia constituye una cuestión ambigua como señalé previamente, también lo es la cantidad porque no se trata solo de números sino de diferentes escalas en la confección y comercialización en un contexto que es la moda. Para la socióloga Johanne Entwistle (2002), estas escalas corresponden a diferentes "sistemas de provisión". Dentro de la moda, que ella define como una industria, distingue dos sistemas o sectores: la ropa exclusiva hecha a medida, propia de la alta costura y la confección masiva. Esta distinción no solo fue señalada por esta autora sino que está presente en la teoría social sobre la moda. A esta 
distinción se refirió Pierre Bourdieu (1990), para quien esta última constituye un campo de producción cultural, en relación a dos sub campos: la producción restringida limitada a los productores y la gran producción orientada a un público ampliado?

Respecto a ambos sistemas o sub campos ¿es posible establecer un límite nítido entre ambos? ¿Cómo determinar cuándo un vestido está orientado al gran público cuando antes se dirigía a uno reducido? Expresado de otra forma, mi inquietud radica en saber de qué forma se desarrolla el proceso por el cual un vestido ingresa al sistema de la confección masiva. En lo que respecta al trabajo de campo realizado, advertí que las escalas de producción entre quienes se identificaban como diseñadores eran más o menos próximas a las indicadas por Marianela. No obstante, cada productor tenía su propia escala que variaba de acuerdo a las circunstancias de su propia forma de producir.

Este es el caso de Anabela. Ella es una egresada de la carrera de DIT (Diseño de Indumentaria y Textil) que se dicta en la Universidad de Buenos Aires ${ }^{10}$. Tras graduarse, obtuvo un premio otorgado por una institución del gobierno municipal de CABA para llevar a cabo su desfile en el BAF Week. Esta institución está dedicada a la promoción de los emprendimientos de diseño. El dinero del premio le permite al ganador solventar los gastos de la confección de ropa desfiladas por las modelos. El programa abona además los honorarios de las modelos, maquilladores, peinadores y musicalizadores.

A fines del 2015, Anabela inauguró su primer local de venta al público en el barrio de Retiro. Previamente, comercializaba su ropa en su showroom ${ }^{11}$. Este consistía en un departamento al cual se accedía tras atravesar un extenso pasillo. A su local recién estrenado me dirigí un caluroso día de enero del 2016. Su socio no estaba presente en la entrevista, un productor de zapatos con quien se había asociado para concretar la apertura.

Tras felicitar a Anabela por tal apertura, le pregunté cómo se presentaba a sí misma. Debido al hecho de que la marca llevaba su nombre, se consideraba una marca de diseño. Aún no creía ser una marca comercial ya que carecía de la estructura de producción y comercialización que tienen las marcas. Específicamente, debería inaugurar más puntos de venta. A fin de incorporar saberes relativos al manejo de un negocio, asistió a unos talleres dictados por la institución que le facilitó el capital para realizar el desfile. La asistencia, obligatoria para seguir participando en el programa, le permitió incorporar esas herramientas administrativas: cálculo de costos, precios y elaboración de balances contables. Tras atender ella misma a un cliente, quise saber cómo producía la ropa. Lo que ella denominaba básicos ${ }^{12}$ se los encargaba a un taller de confección que describió como: las cosas que hago en cantidad. Algunos pantalones eran realizados por unas modistas. Ella se ocupaba personalmente de la moldería de las prendas de sastrería como vestidos ${ }^{13}$. Por temporada, hacía aproximadamente 70 modelos. De cada modelo, elaboraba más de 20 unidades por prenda.

Son dos las cuestiones que fueron tratadas en este primer apartado. En primer lugar, como es valuada moralmente la copia. En segundo lugar, la reproducción. Ambas fueron tratadas como problemas en la sociología y la antropología del arte. Interesado en el tema de la reproducción, Walter Benjamin (1989) destaca como fenómeno de la modernidad lo que llama la "reproductictibilidad técnica" de la obra de arte que, al imponer lo masivo, anula la singularidad y garantía de autenticidad: el aquí y ahora del original. En esta imposición, se produce una progresiva lejanía con el aval de origen de la pieza, una fotografía o 
escultura. Arjun Appadurai e Igor Kopytoff (1990) son dos antropólogos para quienes, sin embargo, la anulación de la singularidad no llega a ser total en la producción masiva de mercancías, entre las cuales se incluyen las obras de arte. La masividad, que torna homogéneo el valor de las cosas, convive en la época actual con la tendencia contraria que es la singularización. Esta implica la distinción cultural de ciertas mercancías dentro de esferas de intercambio: bienes de lujo, reliquias u objetos de colección.

En esta parte del trabajo, describí diferentes escalas en la multiplicación de los modelos de las prendas que los productores confeccionan: Anabela o las marcas en las cuales trabajaron Marianela y Paulina. La confección no está desligada, sin embargo, de la comercialización y el consumo. Con esto quiero decir que las escalas relativas a las reproducciones precisan ser descritas en vinculación con los espacios urbanos donde los modelos se exhiben y venden. Al análisis de estos espacios me dedicaré en el siguiente apartado: la localización del local de venta al público en uno o varios centros comerciales o la vía pública.

\section{Los espacios de comercialización}

Comenzaré esta parte del trabajo señalando que los productores, reconocidos como diseñadores, suelen detentar un único local como Anabela. ¿Que sucede si ella -u otro diseñador-inaugurara un local en un shopping? Aun así podría ser reconocida socialmente como diseñadora por ella misma y otros productores. O bien, estos podrían imputarle el hecho de haberse convertido en una marca de shopping.

Ambas posibilidades se hacen patentes en un video editado por un canal de moda. Es la filmación de una animada fiesta de apertura realizada en el 2011, en un local dentro del "Shopping Alcorta". En el curso de la fiesta, un periodista conversa con Gustavo, el dueño de la marca de zapatos para mujeres a quien el primero presenta como empresario y a su socia como diseñadora textil. Gustavo considera que el shopping es distinto a los otros: es un shopping de diseño que valora a los diseñadores. En consecuencia, no tuvo reparos en concretar la apertura. Son reparos que, según el periodista, sí expresaron otros diseñadores. Respecto a Anabela, ella se identificaba a si misma como una diseñadora que, en virtud de haber recibido asesoramiento en finanzas y marketing, se estaba convirtiendo en una marca chica. No obstante, añadió instantes después, eso no la convertía automáticamente en una marca de shopping. Le pregunté a que se refería:

Anabela: "no me gustaría ser comercial, así como estar llena de locales pero sí creo que está bueno que una marca de diseño, que un diseñador pueda convertirse en una marca. Por ejemplo, FAMA es un caso que está buenísimo porque él [menciona el nombre del diseñador creador de la firma ${ }^{14}$ ] no deja de ser un diseñador y es una marca comercial. Yo no me considero una marca porque me considero en pleno crecimiento. Para ser una marca me falta a nivel comercial, desde tener más puntos de venta hasta ampliar el nivel de producción"

Más allá de las disyuntivas de los productores respecto a cómo les gustaría o pretenden ser reconocidos, es preciso señalar que la apertura de un local en un shopping no constituye 
un paso inmediato sino que depende de muchos factores. En primer lugar y teniendo en cuenta lo indicado por Anabela, ella debería incrementar el volumen de producción de ropa para detentar más locales. A estos factores aludió Armando, el jefe de producto de "Castaneda". Esta es una empresa que gestiona la administración y funcionamiento de tres marcas de indumentaria femenina en Argentina.

A la oficina de Armando, situada a tres kilómetros de la bajada de una autopista en el conurbano bonaerense, me dirigí un día de octubre del año 2015. Era una oficina situada en un centro de distribución donde se concentraban empresas de varios rubros. La oficina formaba parte de un hangar cuyas paredes y techo eran de chapa, al cual se accedía subiendo una escalera de hierro.

$\mathrm{Al}$ presentarme con la secretaria, me hizo pasar a un salón acondicionado con sillones. Armando me saludó y ofreció un café. Tras conversar media hora, quise saber de qué forma decidían, dentro de la gerencia de la empresa, en cuales shopping abrir locales. Tras servirse un café, respondió que eso obedecía a varias variables. En líneas generales, si una marca aspiraba a captar un volumen significativo de compradores, el shopping lo garantizaba. Esta era una garantía de volumen que no se producía en la calle. Esta categoría designa los locales abiertos en la vía pública, que no aseguraban ese volumen de clientes debido a los ocasionales días de lluvia o las situaciones de inseguridad. Las mismas no se producían dentro del centro comercial que contrata empresas de vigilancia privada. Tras unos minutos de conversación, agregó que algunos establecimientos otorgan a las marcas la masividad (la posibilidad de apuntar a varios mercados de consumidores) mientras que otros garantizan el prestigio y la exclusividad.

Dentro de cada shopping, a su vez, la valuación de los pisos es variable. En algunos centros comerciales, hallar locales en los pisos más elevados resulta más costoso para las marcas al ser los más codiciados y onerosos en el alquiler mensual. En otros centros, los precios de los alquileres se incrementan contrariamente en la planta baja. Esta ubicación era la más requerida por las marcas.

La clasificación de las marcas como de shopping no constituye un proceso simple porque el ingreso a estos lugares tampoco lo es. A dicho proceso aludió Mely -la ex gerente de Marketing de Castaneda- quien aludió a una "lista de espera" para que las marcas ingresaran. Una vez producida la entrada, era preciso tener en consideración los metros ocupados por cada local y la facturación mensual exigida a cada una de ellas. De no lograr esa facturación, se les sugería a los dueños desplazarse a pisos menos codiciados o bien desalojar el local definitivamente. En suma, ser una marca de shopping supone ingresar a un mundo que ya esta clasificado según los establecimientos. Pero la clasificación opera al interior de estos, según los espacios recorridos por los visitantes.

Como señala García Canclini (2004) respecto a Mary Douglas y Baron Isherwood (1990), el consumo sirve para pensar el mundo. Mas precisamente, el consumo establece y fija socialmente significados en relación a las mercancías. Respecto a los centros comerciales, es un mundo en el cual la distribución del espacio es pensada al igual que son pensados sus ocupantes y visitantes. En relación a los consumidores, los trabajos sociológicos acerca del espacio y el consumo destacaron invariablemente la figura del "flaneur", termino francés acuñado por Walter Benjamin para referirse al paseo en Paris del siglo XIX como un paseo y experiencia. 
Este término fue retomado, en esos trabajos, para describir como son transitados los espacios de consumo urbanos contemporáneos. Sobretodo, la recorrida por los shopping o malls, como se denomina en Estados Unidos a los paseos de compras. En el caso de Mike Featherstone (1998) el autor se refiere a los centros de compras y sitios turísticos como espacios de sociabilidad en los cuales se adquieren bienes ligados simbólicamente a estilos de vida y status.

Cuando un paseante pasea por un shopping, se detiene en los puestos ubicados en los pasillos ante los locales o se dirige al patio de comidas o las salas de cine. El o ella está recorriendo un espacio que ha sido ya clasificado según las lógicas y las luchas simbólicas entre las marcas que los ocupan. A estas luchas alude Bourdieu (2010) cuando señala que, en una sociedad jerárquica, no hay espacio que no esté jerarquizado. Y estos rangos se expresa, en el espacio físico, en la concentración de determinados bienes y servicios situados en lugares centrales o mas valorizados. El flaneur recorre, en consecuencia, pasajes que fueron jerarquizados. Y esta jerarquización depende de cada shopping porque en cada uno rigen valorizaciones dispares. Debido al hecho de que el shopping es un mundo clasificado socialmente, quienes lo transitan y alquilan locales vendiendo bienes se categorizan a sí mismos y a otros no solo respecto a lo que venden sino a cuánto venden. En definitiva, no basta señalar que Anabela o una marca de zapatos son marcas de diseñador o de shopping sino remitir estas categorías de adscripción a su particular ubicación en un establecimiento. Y dentro del mismo, a determinado piso y a quienes lo recorren.

\section{La copia de la tendencia}

En tercer lugar, el reconocimiento (auto y hétero) de un productor como diseñador se produce a partir de las llamadas tendencias, referidas en el primer apartado de este trabajo. Mas bien, la réplica de las mismas que los nativos llaman copia. La tendencia designa una forma de conocimiento acerca de la indumentaria que prevalecerá en una determinada temporada. Por ejemplo, si transitamos la temporada otoño-invierno del 2017, la tendencia correspondería a la temporada primavera-verano del mismo año o, incluso, a las temporadas del 2018.

La tendencia es una forma de conocimiento que circula globalmente entre diferentes ciudades en torno a los llamados "centros" o "capitales" de moda: París, Londres, Nueva York y Milán (Sally Weller, 2007; Fred Davis, 1992). En estas urbes se difunden las nuevas modas, se origina la novedad a partir de la exhibición de las colecciones en desfiles a los cuales concurren compradores. Esta novedad genera lo que Davis llama el "proceso" o "ciclo" de la moda que incluye etapas como la difusión de un novedad, saturación, declinación y obsolescencia. Es un proceso en el cual intervienen los compradores indicados al igual que editores, periodistas y publicistas. En suma, un conjunto de personas conscientes de los vaivenes de la moda.

Esta forma de conocimiento económico, compleja y multidimensional, como la describe Weller, se expresa en los catálogos y las revistas en sus formatos gráficos y digitales. Se difunde globalmente como flujos en función de una cierta configuración témporo-espacial dentro de la industria textil. Constituye una configuración anclada en el poder y la posi- 
ción diferencial de quienes participan en tal industria. Consiste en un poder y posición relativa en torno a la gravitación de lugares y localizaciones "centrales y claves" -los centros señalados- en las cuales participa una comunidad implicada en tal conocimiento.

Los estudios acerca de como se difunden los estilos de vestir son fundantes en la sociología de la moda y el consumo. En los primeros modelos "clásicos" (uno de los mas reconocidos fue el propuesto por Georg Simmel llamado "trickle down"15) se proponía que las modas se difundían de arriba hacia abajo: las clases altas imponían estilos luego imitados por las clases bajas. Estos modelos fueron reemplazados por planteos mas complejos, no necesariamente basados en la división de clases. De acuerdo a la socióloga Diana Crane (1999) quien elabora un recuento de estos estudios, la difusión no solo tiene que ver con la diferencia entre clases sociales sino con cuestiones generacionales: grupos de edad o determinadas minorías que imponen estilos en centros urbanos. Por otra parte, la difusión global de los estilos de vestir se caracteriza actualmente por un situación de descentralización. Esto significa que París y Londres ya no son las únicas capitales de moda aunque no perdieron su relevancia. Debido a tal descentralización, la autora destaca el desarrollo de empresas dedicadas a la predicción de lo que prevalecerá en futuras temporadas en base a la información recolectada por sus empleados, al recorrer circuitos comerciales de diferentes ciudades.

Quienes trabajan en empresas situadas en Argentina, viajan ellos mismos -o parte de su personal- a las ciudades reconocidas como "centros" donde asisten a desfiles o ferias en las cuales toman fotografías en celulares y computadoras portátiles. Este viaje se llama de producto o de tendencia $y$, como resultado del mismo, se desarrollan las colecciones de temporada. Al contactarla, Paulina me advirtió precisamente que debíamos concretar el encuentro después de su propio viaje que planeaba hacer en enero. En otras ocasiones, debí aplazar otras entrevistas porque el diseñador o jefe de producto con quien me iba a reunir también debía hacerlo. O lo realizaba el jefe y el diseñador desarrollaba la colección en función de las prendas o catálogos traídos. Algunos diseñadores recordaban esa planificación con cierto fastidio por haber tenido que copiar ropa hecha por otro. Un viaje del cual pretendían distanciarse al iniciar su propia marca.

¿Cómo un diseñador instituye socialmente esa distancia cuando afirma que está en camino de ser una marca? ¿Cómo los actores que participan en la moda distinguen, en un desfile, las colecciones de los diseñadores o marcas? Estos fueron los interrogantes que invariablemente planteé en mis entrevistas a periodistas como es el caso de Lina quien, asimismo, es editora de varias revistas y suplementos de moda. Con ella me reuní en una confitería situada en la intersección de las avenidas Santa Fe y Coronel Díaz. Lina concurría asiduamente a los desfiles realizados en el BAF Week (la "semana de la moda" de Buenos Aires) en los cuales se acomodaba en la primera fila reservada a los miembros acreditados de prensa. En su condición de espectadora, quise saber cómo reconocía las diferencias entre los productores. Replicó que las colecciones de los diseñadores eran innovadoras y no seriadas. Las colecciones de las marcas de shopping, por su parte, se limitaban a mostrar tendencia mas allá de que contrataran diseñadores en su plantel de empleados. Respecto a esta última, quise saber si se refería a la tendencia mundial o la que prevalece en un centro urbano como CABA. Ella replico que, de hecho, las tendencias que llegaban a CABA provenían de otros centros para añadir que no la consideraba como un centro. 
¿De que modo una ciudad es ponderada como centro? Stella Bruzzi y Pamela Church Gibson (2013) plantean que París lo es (junto con otras tres ciudades como Londres, Nueva York y Milan) en función de una formación histórica urbana que, en función de una difusión sostenida de la prensa, le otorgó una superioridad simbólica, económica y política respecto a otras metrópolis. Solo dando cuenta de esta formación en función de la cual se distinguen ciertas ciudades es posible comprender la relevancia de la tendencia en mi investigación. Si bien se ha ampliado el número de ciudades influyentes, no todas constituyen centros de moda reconocidos. En este sentido, Frederic Godart (2014) señala que las ciudades obtienen reconocimiento interviniendo en una arena donde compiten globalmente, excluyendo a algunas al no participar en el flujo de información sobre estilos de vestir.

Para los diseñadores que trabajan en marcas, la referencia a los centros de moda y la información difundida entre éstos se hace presente en su cotidianidad cuando deben realizar el viaje indicado. ¿Qué sucede cuándo los diseñadores crean su propia marca? Respecto a esta cuestión, planteada previamente, Vanina señaló que debía incluir en sus colecciones las cadenas doradas aunque le disgustaran. Por su parte, Vivi es una diseñadora egresada de la carrera de DIT que, en todas las entrevistas, negaba sistemáticamente ser una marca comercial aunque le resultaba difícil evitarlo. A ella la conocí en el 2005, tras asistir a uno de sus desfiles. Mientras me mostraba un perchero en su showroom situado en el barrio de Belgrano, señaló que esa dificultad radicaba en no hacer prendas de moda y, no obstante, procurar que estas se vendieran.

Recordé entonces la primera vez que acudí al primer local de Vivi, situado en el barrio de Palermo, a unas cuadras de Palermo Soho. En ese entonces, equiparó la moda con la tendencia, con un mandato que viene de afuera. En el curso del mismo año, me reuní con Lila cuyo local se situaba en la misma área dentro del barrio. Al igual que Vivi, Lila nació en la primera mitad de la década de 1970. Lila conocía a Vivi y pondero sus prendas de sastrería. La describió como una diseñadora que: hace lo que se le canta. No pude menos que reírme con este comentario y Lila se rió conmigo, aclaro que a Vivi no le interesaba si vendía o no lo que producía. Ella misma se describió como un diseñador "intermedio":

Lisa "soy intermedio porque soy un diseñador que se está metiendo en la cadena comercial sin dejar de ser diseño de autor, no quiero perder eso. Vivi es una diseñadora pura y neta. O sea, no se va a mover de ahí. Son diseñadores que hacen lo que se les canta".

Barbara: "Vivi tiene su propio local, ¿puede realmente hacer lo que se le canta, lo que quiere?"

Lisa "vos podés hacer lo que se te canta cuando tenés un local y no tenés venta mayorista. Si vos tenés solo un local, hacés lo que se te canta. Lo vendés o no vendés. Vas generando como tu clientela que es chiquitita y es un negocio chico. Cuando te metiste en la cadena comercial, es como que empezás a ampliarlo".

Al compararse con Vivi, Lila describió su negocio, la escala en la cual producía y comercializaba la ropa. Al inicio de la conversación, celebró la apertura de su local en el "Alcorta Shopping”. Unos meses antes, había inaugurado otro en el "Shopping Unicenter". Respecto 
a ambas aperturas, reafirmó ser una marca de diseño dentro de un lugar comercial como el shopping donde se copia todo. Estaba por preguntarle si ella también copiaba al haberse incorporado a ese lugar. Negó con la cabeza y añadió que, si bien tenía en cuenta la tendencia mundial, sus colecciones eran únicas en el sentido de que diseñaba absolutamente todo. $\mathrm{Al}$ inicio de este escrito me referí a la adscripción, en función de la perspectiva de Fredrik Barth (1979) acerca de los límites. Estos se mantienen a pesar de las situaciones de contacto social producidas entre individuos de diferentes culturas. Los marcadores de identificación persisten a pesar de la interacción interétnica. Si bien este trabajo no trata precisamente acerca de las identidades étnicas, la idea de límite resulta operativa para reflexionar como el mismo productor que celebra la inclusión dentro de un shopping, reafirma el límite que lo distancia de las marcas que comercializan en este espacio. Esta reafirmación solo se comprende si recordamos que la copia es objetada moralmente en la moda. Esto es, que se reivindique la condición de diseñador y que lo hagan quienes están en potencial situación de "contaminación" por el hecho de estar ligados a la tendencia.

La noción de contaminación fue señalada por la antropóloga Mary Douglas (1973) en "Pureza y Peligro" en relación a situaciones que subvierten un orden en la vida social y trastocan determinados valores morales. En estas situaciones es donde se reivindican categorías sociales, con el objetivo de imponer orden en un entorno como la producción y comercialización de ropa.

De acuerdo a John Heskett (2002), el diseño puede ser considerado algo decorativo y banal si atendemos a la forma en la cual es tratado en revistas de decoración, signado además por los ciclos de la moda. Lejos de ser banal y según lo desarrollado en este trabajo, el diseño y la moda implican procesos de identificación y estos se complejizan cuando las personas que producen ropa se desplazan en el espacio social, viajan a otras ciudades, realiza fiestas de apertura de locales en shopping o incrementan el volumen de ropa confeccionada.

\section{Comentarios conclusivos}

Podría decir que la adscripción es un proceso complejo, que depende de diversas dimensiones algunas de las cuales fueron exploradas en este artículo, pero eso sería puntualizar lo obvio. Mas bien prefiero señalar cuáles fueron las cuestiones tratadas en este artículo, a partir de mi investigación. Asimismo, cómo estas cuestiones se articulan con temáticas que ya fueron tratadas en la sociología y antropología.

En primer término, la diferencia entre diseñador y marca se funda en los volúmenes de producción producidos. Pero esto da lugar a entender las condiciones en las cuales se produce como, por ejemplo, la admisión de ciertos pedidos en talleres de confección. Estos talleres aceptan o rechazan los pedidos en función de las escalas que sus dueños manejan. En este sentido, uno de los comentarios recurrentes, en el curso del trabajo de campo, que algunos talleristas privilegiaban los pedidos de marcas grandes en desmedro de los encargos de diseñadores. Nos encontramos aquí con la temática de la reproductictibilidad técnica tratada por Walter Benjamin. Más precisamente, de qué forma la producción de ropa comprende varias escalas de reproductictibilidad. Entre lo masivo y lo singular como extremos, encontramos diferentes variantes al momento de elaborar ropa. 
En segundo término, ser una marca de diseñador en vías de ser reconocida como marca de shopping como formas de adscripción constituye una temática que remite a la sociología del consumo y las compras que se desarrollan en espacios urbanos. Los trabajos inscriptos en tal sociología centraron su atención en los circuitos de consumo que incluyen el shopping, el mall o los locales comerciales en la vía pública. En estos trabajos se analizó como se desarrollaba la compra como experiencia. En base a cuáles criterios compraban las personas. Mi planteo en este trabajo es que la compra debe ser analizada teniendo en cuenta su inscripción en espacios ya jerarquizados y clasificados según las marcas que los ocupan. Mas aun, los análisis del consumo en espacios como los shopping, Palermo Soho u otras áreas dentro de CABA deben ser llevados a cabo teniendo en cuenta como las marcas se han instituido como una de las principales formas de clasificación contemporáneas. No se compra solo un vestido negro sino un vestido que forma parte de una marca, la cual está asociada a varios significados sociales.

La tercera temática tratada fue la difusión de las modas y las moralidades asociadas a tal difusión. Esto nos remite al tema de la copia y la reproducción mencionadas previamente. Sobretodo, en que consiste la autenticidad como valor y quienes ensalzan tal valor en la moda donde, señaló Balacescu, la copia es realizada cotidianamente aunque no siempre sea posible admitir tal hecho. Pero también la copia tiene que ver con la configuración geográfica de los centros de moda en las cuales se inscribe Buenos Aires. La categoría nativa "tendencia" implica, en sí, el análisis de cómo se divulga la moda como flujos de información y quienes intervienen en esta divulgación.

\section{Notas}

1. Se entiende por categorías "nativas", según Guber (2001), expresiones que adquieren una significación distintiva en la sociedad estudiada por el etnógrafo. Es decir, adquieren una significación en el contexto de la lógica local.

2. Se denomina "productor" o "estilista" a la persona encargada de organizar un desfile que implica la selección de las modelos, la musicalización y la coreografía. Asimismo, el conjunto de prendas que se van a exhibir. Puntualmente en esta última elección se realiza en conjunto con el diseñador.

3. La participación, en articulación con la observación, implica formar parte de las actividades que realizan los miembros de la población en estudio. El énfasis recae en la experiencia vivida por el investigador. En mi caso, la participación implicó asistir a desfiles como espectadora. No solo asistí a la exhibición de la ropa sino que me involucré en el momento posterior a la misma. Esto es, el momento en el cual los asistentes se sacan fotos y conversan entre si.

4. Se denomina jefe de producto a la persona que, en una empresa, está a cargo del departamento de producto en el cual se coordinan instancias de la confección como la realización de moldes, muestras, la costura, adición de avíos, planchado y distribución de las prendas en locales. Asimismo, la persona a cargo asiste a los locales para llevar el recuento de las prendas que se venden. 
5. Los nombres de los informantes y las empresas donde trabajaron y trabajan actualmente fueron cambiados para preservar su privacidad.

6. Es una característica a destacar es que una gran parte de los productores a quienes entrevisté decidieron registrar su empresa utilizando su propio nombre y apellido.

7. Con esta categoría, designan algo a ser vendido en el mercado que tanto puede ser una prenda de vestir como cualquier otra mercancía. En este sentido, los diseñadores que realizan prendas para otros llaman a lo que entregan como producto terminado.

8. Con esta denominación, se alude a un área del barrio de Palermo en las cuales predominan las mueblerías, galerías de arte, tiendas de ropa y artículos de decoración. Esta circunscrita por las avenidas Santa Fe, Córdoba, Scalabrini Ortiz y Juan B. Justo. En ocasiones, también se la llama "Palermo Viejo". La razón del título "Soho" se explica por una referencia a un distrito homónimo dentro de las ciudades de Londres y Nueva York.

9. Para Bourdieu, la moda constituye un campo de producción cultural en el cual se libra una lucha entre los agentes por la apropiación del capital legítimo que es la magia de la firma del productor sobre una pieza: una obra de arte o un vestido. Pero la magia, señala el autor, no la produce el artista o modisto sino los agentes que le otorgan un poder creador. 10. La carrera, cuyo plan de estudios se creó en 1988, se dicta en la Facultad de Arquitectura, Diseño y Urbanismo que forma parte de la Universidad señalada donde se dictan seis carreras. Actualmente, se dicta la misma carrera en otras instituciones educativas universitarias y terciarias.

11. El showroom refiere a un espacio (departamento, casa o estudio) en el cual el productor recibe a sus clientes. Significa espacio de exhibición en inglés y se distingue del local de venta al público. También se llama showroom a los puestos que se instalan en el hall central del pabellón donde se desarrolla el BAF Week (Buenos Aires Fashion Week). El mismo es un evento que se lleva a cabo bienalmente en el Predio Ferial de Palermo desde el año 2000. 12. Se denomina básico a prendas como un pantalón de jean o una remera. Se las llama así en el sentido de ser vestibles. Otra categoría nativa referida a la combinación. Esto es, el hecho de ser una prenda fácilmente combinable con otras prendas.

13. La moldería constituye la instancia de producción de moldes. Las mismas consisten en planchas de papel que corresponden a las piezas de una prenda. Actualmente, los moldes también se realizan mediante programas de computación.

14. Se trata de un diseñador egresado de la carrera de DIT. UBA, nacido en 1970. En el 2002, inició su emprendimiento en el cual, como característica saliente de su producción, realiza combinaciones de diferentes tejidos.

15. En este modelo, que podría ser traducido aproximadamente como "goteo hacia abajo", Georg Simmel plantea que las modas son modas de clase, son el producto de la separación clasista. Esto significa que las modas de la clase superior se diferencian de las clases inferiores y son abandonadas por aquellas cuando estas se las apropian.

\section{Lista de referencias bibliográficas}

Appadurai, A. (1990). La vida social de las cosas. Perspectiva cultural de las mercancías. Arjun Appadurai, eds. Editorial Grijalbo. México. 
Balacescu, A. (2005). "After Authors. Sign(ify)ing Fashion from Paris to Tehran”. En: Journal of Material Culture. Vol. 10(3): 289-310.

Barth, F. (1976). Los grupos étnicos y sus fronteras. Fondo de Cultura Económica. México.

Benjamin, W. (1989). "La obra de arte en la época de su reproductibildad técnica". En: Discursos Interrumpidos I. Editorial Taurus. Buenos Aires

Bourdieu, P. (1990). “El campo literario. Prerrequisitos críticos y principios de método". En: Revista Criterios. La Habana, no 25-28, enero 1989-diciembre 1990, pp. 20-42

Bourdieu, P. (2010). "Efectos de lugar". En: La miseria del mundo. Fondo de Cultura Económica. Buenos Aires.

Bruzzi, S. y Church Gibson, P. (2013). Fashion Cultures Revisited: Theories, Explorations and Analysis.

Guber, R. (2001). La etnografia. Método, campo y reflexividad. Grupo Editorial Norma. Bogotá.

Guber, R. (2004). El salvaje metropolitano: reconstrucción del conocimiento social en el trabajo de campo. Paidos. Buenos Aires.

Godart, F. (2014). “The power structure of Fashion Industry: Fashion Capitals, Globalization and creativity”. En: International Journal of Fashion Studies. Volume 1. Number 1.

Davis, F. (1992). Fashion, Culture and Identity. The University of Chicago Press.

Douglas, M. y Isherwood, B. (1990). El mundo de los bienes. Hacia una antropología del consumo. Editorial Grijalbo. México.

Douglas, M. (1973). Pureza y Peligro. Un análisis de los conceptos de contaminación y tabú. Siglo XXI. México.

Entwistle, J. (2002). El cuerpo y la moda. Una vision sociológica. Editorial Paidos. Barcelona.

Featherstone, M. (1998). “The Flâneur, the City and Virtual Public Life”. En: Urban Studies, Vol. 35, Nros. 5-6, 909-925

García Canclini, N. (1999). "El consumo sirve para pensar". En Constructores de Otredad. Boivin, M., Rosato, A. y Arribas, V. Editorial Antropofagia. Buenos Aires.

Heskett, J. (2002). El diseño en la vida cotidiana. Editoria Gustavo Gili. Barcelona.

Levi-Strauss, C. (1981). La identidad. Ediciones Petrel. Barcelona.

Simmel, G. (1999). "La moda”. En: Cultura femenina y otros ensayos. Alba editorial. Barcelona. Weller, S. (2007). Fashion as viscous knowledge: fashion's role in shaping trans-national garment production. Journal of Economic Geography, 7(1):39-66.

\begin{abstract}
The goal of this article is to understand the development of social process identification. These dynamics are based on the way a group of clothing producers (garment, footwear and accessories) participate in biannual fashion events and exhibitions. This works builds upon my ethnographic fieldwork for my Phd thesis. Precisely during my fieldwork I noticed the relevance of two categories: brand and designer. These categories related to the way producers publicly identify among themselves. This identification is associated to the number of garments that conforms the season collection. Besides it is related to the social spaces where producers commercialize the garments and also to the moral imputations about the often-called copia. The copia presumably expresses more or less, the influence of global fashion trends.
\end{abstract}


The producers recognized as designers would like to remain isolated for these trends. On the other hand, their collections include less garment that the brand's collections. In addition, brands typically sell in shopping, mall located throughout CABA and the metropolitan area. But this distinction is questioned in several contexts, leading to the articulation between the categories of brand and designer. The present article describes this articulation.

Key words: design - fashion - clothing - production - commercialization.

Resumo: O objetivo do presente artigo consiste em compreender de que forma se desenvolvem os processos sociais de atribuição na moda, em função de como um grupo de produtores de indumentária (vestimenta, calçado e acessório) intervém em eventos e exibições bianuais de moda. Este artigo baseia-se no meu trabalho de campo etnográfico realizado para a tese de doutorado. Foi durante a elaboração desse trabalho que entendi a relevância de duas categorias: marca e design. Estas categorias se remetem na forma em que os produtores se identificam publicamente entre eles. Constitui em uma identificação relativa ao volume de roupa incluída na produção de temporada, aos espaços sociais onde comercializam a roupa, assim como as imputações morais em relaçãoà presença da chamada cópia. Esta cópia expressa a maior ou menor influência das tendências internacionais da moda num produto próprio ou a carência das características próprias do designer. Aqueles que são reconhecidos como designers, pretendem estar distanciados dessas tendências. Por outro lado, suas coleções incluem menos prendas que as marcas, as quais se caracterizam por vender-se em shoppings, centros comerciais localizados em CABA e na área metropolitana. Más esta distinção esta sendo questionada em vários contextos, levando a que as categorias de marca e design se articulem entre si. Neste artigo descrevo a mencionada articulação.

Palavras chave: design - moda - indumentária - produção - comercialização. 